\title{
Higher insulin sensitivity in EDL muscle of rats fed a low-protein, high-carbohydrate diet inhibits the caspase- 3 and ubiquitin-proteasome proteolytic systems but does not increase protein synthesis
}

\author{
Maísa Pavani dos Santos ${ }^{\mathrm{a}}$, Emanuele Batistela ${ }^{\mathrm{a}}$, Mayara Peron Pereira ${ }^{\mathrm{a}}$, Silvia Paula-Gomes ${ }^{\mathrm{b}}$, \\ Neusa Maria Zanon ${ }^{\mathrm{b}}$, Isis do Carmo Kettelhut ${ }^{\mathrm{b}}$, Christina Karatzaferi ${ }^{\mathrm{c}}$, Claudia Marlise Balbinotti Andrade ${ }^{\mathrm{a}}$,

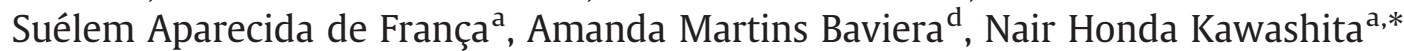 \\ ${ }^{a}$ Department of Chemistry, Federal University of Mato Grosso, Cuiabá, Mato Grosso, Brazil \\ ${ }^{\mathrm{b}}$ Department of Biochemistry and Immunology, School of Medicine, University of São Paulo, Ribeirão Preto, São Paulo, Brazil \\ ${ }^{\mathrm{c}}$ Faculty of Sport and Health Sciences, University of St Mark and St John, Plymouth, United Kingdom \\ ${ }^{\mathrm{d}}$ Department of Clinical Analysis, School of Pharmaceutical Sciences, São Paulo State University, Presidente Prudente, São Paulo, Brazil
}

Received 30 November 2015; received in revised form 12 April 2016; accepted 23 April 2016

\begin{abstract}
Compared with the extensor digitorum longus (EDL) muscle of control rats (C), the EDL muscle of rats fed a low-protein, high-carbohydrate diet (LPHC) showed a $36 \%$ reduction in mass. Muscle mass is determined by the balance between protein synthesis and proteolysis; thus, the aim of this work was to evaluate the components involved in these processes. Compared with the muscle from C rats, the EDL muscle from LPHC diet-fed rats showed a reduction (34\%) in the in vitro basal protein synthesis and a $22 \%$ reduction in the in vitro basal proteolysis suggesting that the reduction in the mass can be associated with a change in the rate of the two processes. Soon after euthanasia, in the EDL muscles of the rats fed the LPHC diet for 15 days, the activity of caspase- 3 and that of components of the ubiquitin-proteasome system (atrogin-1 content and chymotrypsin-like activity) were decreased. The phosphorylation of p70 ${ }^{\mathrm{S} 6 \mathrm{~K}}$ and $4 \mathrm{E}-\mathrm{BP} 1$, proteins involved in protein synthesis, was also decreased. We observed an increase in the insulin-stimulated protein content of p-Akt. Thus, the higher insulin sensitivity in the EDL muscle of LPHC rats seemed to contribute to the lower proteolysis in LPHC rats. However, even with the higher insulin sensitivity, the reduction in p-E4-BP1 and $\mathrm{p} 70^{\mathrm{S} 6 \mathrm{~K}}$ indicates a reduction in protein synthesis, showing that factors other than insulin can have a greater effect on the control of protein synthesis.
\end{abstract}

(c) 2016 Elsevier Inc. All rights reserved.

Keywords: Low-protein, high-carbohydrate diet; Protein synthesis; Proteolytic pathways; Extensor digitorum longus; Insulin sensitivity; Growing rats

\section{Introduction}

In developing countries, malnutrition is an early and usual event in the human life. Normally, children in these countries consume a great amount of carbohydrates and a small quantity of protein, which can lead to structural damage in several organs and increased mortality [1,2].

Skeletal muscle is considered the most abundant tissue in the body, making up approximately $40-50 \%$ of the total body mass and serving as the largest body protein pool [3,4]. Skeletal muscle exhibits a high resting metabolic rate and is one of the most adaptable tissues responding to numerous external and physiological stimuli [5], which induce changes in its phenotypic profile in terms of size and composition [6]. Thus, particularly in conditions of protein malnutrition, the adaptations of muscles are fundamental to body homeostasis.

Several authors have suggested that protein restriction during the critical stage of development results in a reduction in the skeletal

\footnotetext{
* Corresponding author. Tel.: +55-65-3615-8765; fax: +55-65-36158005.

E-mail address: nairhonda@terra.com.br (N.H. Kawashita).
}

muscle mass and in the number and size of fibers [7,8], along with higher vulnerability to atrophic reactions [9]. However, other authors have shown that muscle fibers are capable of adapting their metabolism, optimizing protein turnover to preserve the primary functions in malnutrition conditions [10-12].

Studies from our research group showed that rats that were fed a low-protein, high-carbohydrate diet (LPHC; 6\% protein and $74 \%$ carbohydrate) for 15 days soon after weaning showed an increase in the diet and calorie intake with a reduction in the body weight gain compared to the corresponding factors in the rats fed a control diet (C; $17 \%$ protein and 63\% carbohydrate) [13]. Even when the increase in the food intake was accounted for, the LPHC rats ingested $60 \%$ less protein than the rats fed the $C$ diet at the end of 15 days, which was confirmed by the reduced postprandial amino acid concentration in the blood of these rats [13]. The protein-deficient state in LPHC rats could also be indicated by the hypoproteinemia and impairment in the body growth (evaluated by Lee index) compared to the condition of the rats receiving a C diet [13]. Moreover, LPHC rats showed a reduction in the body mass with a higher energetic gain as a consequence of an increase in the body lipid content and a reduction in 
the water and protein contents [13] (data are shown in Table S1 of the supplementary material). Additionally, the LPHC diet promotes an increase in serum epinephrine and norepinephrine levels, as well as 10 times higher levels of tumor necrosis factor alpha (TNF- $\alpha$ ) and 100\% higher levels of corticosterone and leptin $[13,15,16]$ (data are shown in Table S2 of the supplementary material); thus, the LPHC diet seems to promote a highly catabolic environment. A previous study also showed a reduction in the mass of different skeletal muscles in LPHC rats compared with $C$ rats [13].

The mass and protein content of skeletal muscle are determined by the dynamic equilibrium between the rates of protein synthesis and proteolysis [6]. In addition to the availability of essential amino acids, insulin and the insulin-like growth factor (IGF-1) are considered to be factors that mediate normal muscle development $[17,18]$. These factors bind with their respective receptors, resulting in activation/ phosphorylation of protein kinase B, also known as Akt. Akt stimulates protein synthesis by activating the mammalian target of rapamycin (mTOR) and its downstream effectors and inhibits glycogen synthase

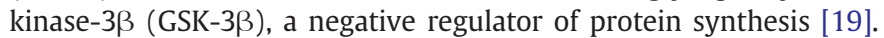
Activation of Akt also induces the phosphorylation of the forkhead box transcription factor (Foxo) and its subsequent nuclear exclusion, which results in the inhibition of atrogene transcription and consequently in the inhibition of proteolysis [20].

In turn, there are different proteolytic systems in cells. Intracellular proteolysis may occur in lysosomes after fusion with the autophagosome, which requires the expression of microtubule-associated protein 1 light chain 3 beta (LC3) and gamma-aminobutyric acid receptor-associated protein (GABARAP). The proteolytic capacity of the lysosomes is determined by the activity of cathepsins L, B, D and $\mathrm{H}$ [21]. Extralysosomal proteolytic pathways in the skeletal muscle cells of mammals include the calpains or $\mathrm{Ca}^{2+}$-dependent proteases, caspase- 3 and the ubiquitin-proteasome proteolytic system [14]. The specificity in protein breakdown by this last proteolytic system is dependent on the content of ubiquitin ligase enzymes (E3s). Two E3s, muscle F-box protein (atrogin-1 or MAFbx) and the protein muscle RING finger-1 (MuRF-1) are known as atrogenes, and they play a decisive role in mediating the loss of muscle mass [20]. Studies indicate the participation of calpains and caspase- 3 in the dissociation of actin and myosin from myofibrils before they are degraded by the proteasome $[22,23]$.

A previous study on soleus muscles of LPHC rats showed that the reductions in mass and protein content resulted from decreases in protein synthesis [14] and overall proteolysis. The proteolysis was reduced mainly due to inhibition of both the ubiquitin-proteasome system and caspase-3 activity [14]. The results also indicated higher insulin sensitivity in the soleus muscles of the LPHC rats, which was evidenced by increases in the insulin receptor content and in insulin-stimulated Akt phosphorylation [14], suggesting that the higher insulin sensitivity in the soleus muscle of the LPHC rats was responsible for the inhibition of the proteolytic processes.

However, the alterations observed in the protein metabolism of the soleus muscles from LPHC rats are not necessarily valid for other skeletal muscles because the metabolic response in different metabolic situations seems to be muscle-type specific. Differences in the sensitivity of skeletal muscles to dietary manipulations have also been reported by several authors. Mizushima et al. [24] showed that transgenic mice subjected to nutrient starvation experienced rapid and intense macroautophagy in the extensor digitorum longus (EDL) muscle, which almost exclusively contains fast-twitch fibers (glycolytic, type II), and experienced moderate and slow macroautophagy in the soleus muscles, which contains a high percentage of slow-twitch fibers (oxidative, type I). Furthermore, the regulation of extralysosomal proteolytic pathways can differ in skeletal muscles with different fiber-type compositions [25,26].
Thus, the aim of this study was to evaluate the effect of the LPHC diet on components of the systems for protein synthesis and proteolysis as the first stage in establishing possible mechanisms that explain the reduced mass of EDL muscle. For this purpose, we evaluated the following in EDL muscles from control and LPHC rats: (1) mass and protein content of the EDL muscle; (2) in vitro basal protein synthesis and proteolysis; (3) protein contents and enzyme activities related to proteolytic pathways; (4) insulin signaling pathway protein content; (5) basal and phosphorylated contents of 4E-BP1, p70 ${ }^{\mathrm{S} 6 \mathrm{~K}}$, GSK-3 $\beta$, CREB and AMPK, which are proteins involved in the regulation of protein synthesis; and (6) basal and phosphorylated content of Foxo1, which is involved in the regulation of proteolysis.

\section{Methods and materials}

\subsection{Animals and treatment}

The animals used in the experiments were provided by the Central Animal House of Universidade Federal de Mato Grosso (UFMT). The animals were handled according to the Brazilian College of Animal Experimentation Regulations, and the experiments were approved by the Animal Ethics Committee of UFMT (protocol no. 23,108.043335/08-1). Male Wistar rats (5-10 animals) with an initial body weight of approximately 90-100 g ( 30 days old) were randomly distributed into two groups: (i) control group (C) that was fed a diet composed of $17 \%$ protein, $63 \%$ carbohydrate and $7 \%$ lipid and (ii) LPHC group that was fed a diet composed of $6 \%$ protein, $74 \%$ carbohydrate and $7 \%$ lipid. The reduction of protein in the LPHC diet, in term of calories, was compensated by carbohydrates (Table 1). The diets are isocaloric $(16.3 \mathrm{~kJ} / \mathrm{g}$ ) and were administered for 15 days. The rats were housed in individual metabolic cages at $22 \pm 1{ }^{\circ} \mathrm{C}$ with a $12 \mathrm{~h}: 12 \mathrm{~h}$ light:dark cycle; they also received water and food ad libitum. The body weight and food intake of each rat were recorded daily. All rats were euthanized on the 15th day of treatment, and the EDL muscles were collected, weighed and stored at $80^{\circ} \mathrm{C}$ or immediately used in experiments.

\subsection{Total protein content of the EDL skeletal muscle}

For the LPHC and C fed rats, both EDL muscles (right and left) were used for the analysis. The muscles were minced and homogenized using a glass-Teflon homogenizer (Wheaton Overhead Stirrer) in buffer containing $50 \mathrm{mM}$ potassium phosphate dibasic, $5 \mathrm{mM}$ EDTA, $0.5 \mathrm{mM}$ DTT, $1.15 \% \mathrm{KCl}, 1 \mathrm{mM}$ phenylmethyl sulfonyl fluoride, $5 \mu \mathrm{g} / \mathrm{ml}$ aprotinin and $1 \mu \mathrm{g} / \mathrm{ml}$ leupeptin at $\mathrm{pH} 7.4 \mathrm{in}$ a proportion of $4 \% \mathrm{wt} / \mathrm{vol}$. The homogenate was centrifuged at $600 \mathrm{~g}$ for $10 \mathrm{~min}$ at $4^{\circ} \mathrm{C}$. The total protein content was determined by the Bradford method [27], and the data are expressed in milligrams per gram muscle.

\subsection{In vitro, basal protein synthesis and proteolysis}

Groups of rats were treated with the C or LPHC diet. After 15 days of treatment, the animals in the fed state were euthanized, and the muscles were removed and incubated for the in vitro evaluation of the protein synthesis. The same process was performed with another set of rats from the C and LPHC groups for the evaluation of muscle proteolysis.

The EDL muscles were rapidly dissected, weighed and fixed by the tendon in appropriate supports (to maintain the muscles at the resting length) and were incubated in Erlenmeyer flasks ( 1 muscle/flask) containing Krebs-Ringer bicarbonate buffer $\left(0.120 \mathrm{M} \mathrm{NaCl}, 0.015 \mathrm{M} \mathrm{NaHCO}_{3}, 4.828 \mathrm{mM} \mathrm{KCl}, 1.2 \mathrm{mM} \mathrm{MgSO}_{4}, 1.212 \mathrm{mM}\right.$ $\mathrm{KH}_{2} \mathrm{PO}_{4}$ and $2.4 \mathrm{mM} \mathrm{CaCl}_{2}$ at $\mathrm{pH} 7.4$ ) and $5 \mathrm{mM}$ glucose, aerated with $95 \% \mathrm{O}_{2}$ and $5 \%$ $\mathrm{CO}_{2}$.

Table 1

Compositions $(\mathrm{g} / \mathrm{kg}$ ) of the control and low-protein, high-carbohydrate diets

\begin{tabular}{|c|c|c|}
\hline Ingredients & Control diet & LPHC diet \\
\hline Casein (84\% protein) & 202 & 71.5 \\
\hline Cornstarch & 397 & 480 \\
\hline Dextrinized cornstarch & 130.5 & 159 \\
\hline Sucrose & 100 & 121 \\
\hline Soybean oil & 70 & 70 \\
\hline Fiber (cellulose) & 50 & 50 \\
\hline Mineral mix (AIN $93 \mathrm{G})^{\mathrm{a}}$ & 35 & 35 \\
\hline Vitamin mix (AIN $93 \mathrm{G})^{\mathrm{a}}$ & 10 & 10 \\
\hline L-Cystine & 3 & 1 \\
\hline Choline bitartrate & 2.5 & 2.5 \\
\hline
\end{tabular}

a For the detailed composition, see Reeves et al. (1993). 
The in vitro basal protein synthesis was evaluated as previously described $[14,28]$. After a 1-h preincubation period at $37^{\circ} \mathrm{C}$ with shaking, the EDL muscles were incubated in the same Krebs-Ringer bicarbonate buffer described above containing all amino acids at concentrations similar to those of the rat plasma during fed period [29] and $\mathrm{L}-\left[\mathrm{U}-{ }^{14} \mathrm{C}\right]$ tyrosine $(0.05 \mu \mathrm{Ci} / \mathrm{ml})$ for $2 \mathrm{~h}$. After the incubation, the specific activity of the intracellular tyrosine pool in each muscle was estimated by measuring the radioactivity and the concentration of free tyrosine. After measurement of the radioactivity incorporated into the protein of the same muscle, the in vitro basal protein synthesis was calculated using the specific activity of the intracellular pool of tyrosine, assuming that there was no recycling of the label during the incubation period [14].

The in vitro basal proteolysis was evaluated as previously described [14,30], by determination of the tyrosine release in the medium. After a 1-h preincubation period at $37^{\circ} \mathrm{C}$ with shaking, the EDL muscles were incubated for $2 \mathrm{~h}$ in the same Krebs-Ringer bicarbonate buffer described above without any amino acids in the medium but with $0.5 \mathrm{mM}$ cycloheximide to prevent protein synthesis and the reincorporation of the released tyrosine back into proteins. At the end of the incubation period, $1 \mathrm{ml}$ of the medium was collected and added to $0.25 \mathrm{ml}$ of perchloric acid $(1.5 \mathrm{~N})$, and the released tyrosine was evaluated using the fluorimetric method described by Waalkes and Udenfriend [31].

\subsection{Enzyme activities}

The activities of caspase-3, calpain, cathepsin B and proteasome (chymotrypsin-like activity) were determined fluorometrically (PerkinElmer) with excitation and emission wavelengths of 380 and $460 \mathrm{~nm}$, respectively. The protein content of the muscle homogenates was determined by the Bradford method [27]. The enzyme proteolytic activities were determined by measurement of the released fluorogenic product (AMC; 7-amino-4-methylcoumarin), and a standard curve of AMC was prepared (Calbiochem). Data are expressed in nanomoles of AMC per milligram of protein per minute.

Chymotrypsin-like proteasome activity was assayed according to Klaude et al. [32]. EDL muscles were homogenized in Tris- $\mathrm{HCl}$ buffer ( $\mathrm{pH} 7.2$ ) containing $50 \mathrm{mM} \mathrm{Tris-HCl}$, $1 \mathrm{mM}$ EDTA, $100 \mathrm{mM} \mathrm{KCl}, 5 \mathrm{mM} \mathrm{MgCl} 2$ and $1.8 \mathrm{mM}$ ATP. The homogenate was centrifuged at $700 \mathrm{~g}$ at $4^{\circ} \mathrm{C}$ for $10 \mathrm{~min}$ to remove cell debris. The supernatant was centrifuged at $15,000 \mathrm{~g}$ for $10 \mathrm{~min}$. Glycerol was then added to the supernatant ( $10 \% \mathrm{vol} /$ vol), which was used to measure the total protease activity. Duplicates of the supernatant were incubated with the assay buffer $(50 \mathrm{mM}$ Tris- $\mathrm{HCl}, 1 \mathrm{mM}$ ATP, $5 \mathrm{mM} \mathrm{MgCl}$ and $1 \mathrm{mM}$ DTT; pH 7.5), and $150 \mu \mathrm{M}$ substrate succinyl-Leu-Leu-Val-TyrAMC (Calbiochem, Germany) was added after 1 min of stabilization. In parallel, the same incubation procedure was performed with the addition of proteasome inhibitor (100 $\mu$ M MG132; Sigma Aldrich) to the mixture. After incubation at $37^{\circ} \mathrm{C}$ for $45 \mathrm{~min}$, the reaction was stopped by the addition of $100 \mathrm{mM}$ sodium acetate buffer ( $\mathrm{pH} 4.3$ ). The proteasome activity was determined by the difference between the amounts of AMC generated in the absence and the presence of MG132.

Calpain activity was assayed according to Douillard et al. [33]. EDL muscles were homogenized in Tris- $\mathrm{HCl}$ buffer ( $\mathrm{pH} 7.4$ ) containing $20 \mathrm{mM}$ Tris-HCl, 5 mM EDTA, 0.1\% Triton X-100 and $1 \mathrm{mM}$ DTT. The homogenates were centrifuged at $1000 \mathrm{~g}$ at $4^{\circ} \mathrm{C}$ for $10 \mathrm{~min}$ to remove cell debris. The calpain activity was measured using the same substrate mentioned above. Duplicates of the supernatant were incubated with the assay buffer ( $20 \mathrm{mM}$ Tris- $\mathrm{HCl}, 5 \mathrm{mM} \mathrm{CaCl}_{2}$ and $1 \mathrm{mM}$ DTT; pH 7.4), and after $5 \mathrm{~min}$, the substrate was added $(50 \mu \mathrm{M})$. In parallel, the same incubation procedure (at $37^{\circ} \mathrm{C}$ for 30 $\mathrm{min}$ ) was performed with the addition of calpain inhibitor (50 $\mu \mathrm{M}$ calpeptin; Santa Cruz Biotechnology) to the mixture (20 mM Tris-HCl, 10 mM EDTA and 1 mM DTT; pH 7.4). The reaction was stopped by the addition of the stop buffer (100 mM sodium chloroacetate, $30 \mathrm{mM}$ sodium acetate and $70 \mathrm{mM}$ acetic acid; $\mathrm{pH} \mathrm{4.3)}$. The calpain activity was determined by the difference between the amounts of AMC generated in the absence and presence of calpeptin.

Caspase-3 activity was determined as described by Du et al. [22], with minor modifications. Briefly, EDL muscles were homogenized in Hepes buffer (100 mM Hepes, $10 \%$ sucrose, $0.1 \%$ Triton X-100 and 10 mM DTT; pH 7.5) and centrifuged at 15,000g for $45 \mathrm{~min}$. The supernatant was added to the assay buffer ( $100 \mathrm{mM}$ Hepes, $10 \mathrm{mM}$ DTT and $10 \%$ sucrose; $\mathrm{pH} 7.5$ ), and the mixture was preincubated at $30^{\circ} \mathrm{C}$ for $30 \mathrm{~min}$. The substrate for caspase-3, Ac-Asp-Glu-Val-Asp-AMC (Calbiochem, Germany), was added $(50 \mu \mathrm{M})$, and the mixture was incubated at $30^{\circ} \mathrm{C}$ for $60 \mathrm{~min}$. The reaction was stopped by

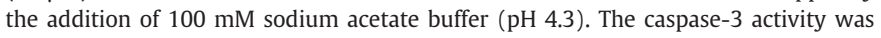
determined considering data from the standard curve of AMC.

Cathepsin B activity was determined as described by Barrett and Kirschke [34]. Briefly, EDL muscles were homogenized in $20 \mathrm{mM}$ sodium phosphate buffer ( $\mathrm{pH} \mathrm{6.0)}$ containing $0.15 \mathrm{M} \mathrm{KCl}$ and $0.1 \%$ Triton X-100 and centrifuged at $15,000 \mathrm{~g}$ at $4^{\circ} \mathrm{C}$ for 10 min. Duplicates of the supernatant were preincubated with assay buffer ( $340 \mathrm{mM}$ sodium acetate, $60 \mathrm{mM}$ acetic acid, $4 \mathrm{mM}$ EDTA and $8 \mathrm{mM}$ DTT; pH 5.5) at $30^{\circ} \mathrm{C}$. After 1 min, $20 \mu \mathrm{M}$ of the substrate for cathepsin B (Z-Arg-Arg-AMC, $2 \mathrm{HCl}$; Calbiochem) was added. The reaction was stopped after $20 \mathrm{~min}$ by the addition of the same stop buffer used in the calpain activity evaluation. The cathepsin B activity was determined considering data from the standard curve of AMC.

\subsection{Insulin signaling study}

Rats from the C or LPHC groups were fasted for $5 \mathrm{~h}$ and were then intraperitoneally injected with saline ( $\mathrm{C}$ and LPHC nonstimulated groups) or insulin $(10 \mathrm{mU} / \mathrm{g}$ body weight; C and LPHC stimulated groups). Ten minutes after the insulin or saline administration, the animals were anesthetized with a mixture of ketamine hydrochloride (Dopalen, Agribrands) and xylazine hydrochloride (Rompun, Bayer) (2:1), and after the loss of pedal and corneal reflexes, the EDL muscles were quickly removed. The protein content of the insulin receptor $\mathrm{IR}_{\beta}$ and Akt and the p-Akt protein content were determined through Western blotting.

\subsection{Western blot for protein analysis}

EDL muscles from $\mathrm{C}$ and $\mathrm{LPHC}$ rats were homogenized in $50 \mathrm{mM}$ Tris- $\mathrm{HCl}$ buffer $\mathrm{pH}$ 7.4 , at $4^{\circ} \mathrm{C}$, containing $1 \%$ Triton $\mathrm{X}-100,150 \mathrm{mM}$ sodium chloride, $10 \mathrm{mM}$ sodium pyrophosphate, $100 \mathrm{mM}$ sodium fluoride, $1 \mathrm{mM}$ EDTA, $10 \mathrm{mM}$ sodium orthovanadate, $1 \mathrm{mM}$ phenylmethyl sulfonyl fluoride and $5 \mu \mathrm{g} / \mathrm{ml}$ aprotinin. The total protein concentration was determined by the Bradford method [27]. For each sample, $100 \mu \mathrm{l}$ of total homogenate was incubated for $5 \mathrm{~min}$ at $100^{\circ} \mathrm{C}$ with Laemmli buffer $(0.250 \mathrm{mM}$ Tris- $\mathrm{HCl}$ buffer at $\mathrm{pH} 6.8,0.5 \%$ bromophenol blue, $50 \%$ glycerol, $10 \%$ sodium dodecyl sulfate and $500 \mathrm{mM}$ dithiothreitol) $(4: 1, \mathrm{vol} / \mathrm{vol})$. Samples containing $100 \mu \mathrm{g}$ of protein were separated by $8-10 \%$ SDS-PAGE, transferred to nitrocellulose membranes and blotted with the following antibodies: anti-cathepsin L (1:500; Santa Cruz), anticathepsin B (1:500; Santa Cruz), anti-ubiquitin conjugates (1:1000; Santa Cruz), antiLC3 (1:1000; Santa Cruz), anti-GABARAP (1:1000; Santa Cruz), anti-AMPK (1:1000; Cell Signaling), anti-phospho-[Thr-172]-AMPK (1:1000; Cell Signaling), anti-IR $\mathrm{R}_{\beta}$ (1:750; Santa Cruz), anti-Akt (1:500; Santa Cruz), anti-phospho-[Ser-473]-Akt1/2/3 (1:500; Santa Cruz), anti-CREB (1:750; Cell Signaling), anti-phospho-[Ser-33]-CREB (1:750; Cell Signaling), anti-Foxo1 (1:500; Cell Signaling), anti-phospho-[Thr-24]-Foxo1 (1:500; Cell Signaling), anti-atrogin-1 (1:1000; c), anti-4E-BP1 (1:500; Cell Signaling), anti-phospho-[Thr-70]-4E-BP1 (1:500; Cell Signaling), anti-p70 ${ }^{\text {S6K }}(1: 500$; Cell Signaling), anti-phospho-[Thr70]-p70 ${ }^{\mathrm{S} 6 \mathrm{~K}}$ (1:500; Cell Signaling), anti-GSK-3ß (1:500; Cell Signaling), anti-phospho-[Ser-21/9]-GSK-3 (1:500; Cell Signaling) and anti- $\alpha$-tubulin (1:750; Santa Cruz). All antibodies used are recommended for the detection of rat proteins. Proteins were detected after membrane incubation overnight $\left(4^{\circ} \mathrm{C}\right)$ in the respective primary antibodies diluted in TBS-T containing $5 \%$ dry albumin. Specific bands were detected with a Supersignal West Pico chemiluminescent substrate (Pierce), and the protein band intensity was normalized to the $\alpha$-tubulin band intensity (internal control). The band intensity was quantified with the Image Program (Wayne Rasband, National Institutes of Health, New York, NY), and the results are expressed as the relative ratio using the internal control as the baseline.

\subsection{Statistical analysis}

All data were expressed as the mean \pm standard error (SE) for the number of rats indicated between parentheses. Statistical analysis was performed using the Statistica Software package (Statsoft, Tulsa, OK). Bartlett's test for the homogeneity of variances was initially used to determine whether the data complied with the assumptions for parametric analysis of variance. When necessary, the data were log-transformed to correct for variance in heterogeneity or nonnormality. All statistical significances of the other experiments were analyzed using Student's $t$ test. The sample size used in all experiments was calculated by considering a $15 \%$ coefficient of variation for the biological effect [35]. A value of $P<.05$ was taken as the criterion for significance.

\section{Results}

\subsection{General physiological and biochemical parameters}

At the end of the 15th day of treatment, the total food intake of the LPHC rats was approximately $13 \%$ higher than that of the control rats. However, despite this increase in the food intake, the total protein intake and final body weight of the LPHC rats were $61 \%$ and $23 \%$ lower, respectively, than the control rats. These data are in agreement with previously published results by our laboratory [13-16].

The reduction in body weight of the LPHC rats was accompanied by a reduction in the mass (36\%) and protein content (34\%) of the EDL muscles (Table 2) compared with the values of the control rats.

\subsection{In vitro, basal protein synthesis and proteolysis}

The in vitro protein synthesis was markedly lower (34\%) in the EDL muscles of the LPHC rats than in the control rats (Fig. 1A). Moreover, the LPHC diet caused a $22 \%$ reduction in the in vitro proteolysis in EDL muscles compared with the values found in control rats (Fig. 1B). 


\subsection{Proteolytic pathways}

Evaluation of the components of the lysosomal system showed that the EDL muscles from the LPHC rats had approximately 52\% higher protein content of cathepsin B (Fig. 2A), without changes in the cathepsin L content (Fig. 2B). Despite the increase in the content of cathepsin B, the activity of this protease was similar between the LPHC and $C$ groups (Fig. 2C). Additionally, there were no differences in the protein contents of the autophagic components, LC3 and GABARAP in the EDL muscles (Fig. 2D) of LPHC rats compared to $C$ rats.

Proteases related to sarcomere structure proteolysis were also evaluated. The LPHC diet had no effect on the calpain activity of EDL muscles (Fig. 3A). However, the activity of caspase-3 was $16 \%$ lower in the EDL muscles of LPHC rats than in the control rats (Fig. 3B).

Data from the ubiquitin-proteasome system evaluation showed that the atrogin- 1 content was $34 \%$ lower in the EDL muscles of the LPHC rats (Fig. 4A). There were no differences in the levels of the ubiquitin conjugates of high and low molecular weight in the EDL muscles (Fig. 4B). The chymotrypsin-like proteasome activity (Fig. 4C) in the EDL muscles was 19\% lower in the LPHC rats than in the control rats.

\subsection{Insulin signaling}

There were no differences in the protein contents of $\mathrm{IR}_{\beta}$ and Akt in the EDL muscles of the experimental groups (Figs. 5A and 5B). In the control rats, the insulin-stimulated Akt phosphorylation was increased by $125 \%$ compared with the noninsulin stimulated value. In LPHC rats, this increase was approximately 230\% relative to the basal LPHC (Fig. 5C).

\subsection{Basal and phosphorylated contents of $4 E-B P 1, p 70^{S 6 K}, G S K-3 \beta, C R E B$ and AMPK (regulation of protein synthesis)}

The evaluation of the contents of protein components involved in the translation process showed that the $4 \mathrm{E}-\mathrm{BP} 1$ content was $50 \%$ higher in EDL muscles from LPHC rats than in C rats; however, the 4EBP1 phosphorylation levels were $42 \%$ lower (Fig. 6A). Similarly, there was a significant reduction (70\%) in the phospho-p70 ${ }^{\mathrm{S} 6 \mathrm{~K}}$ levels in the EDL muscles from LPHC rats, although the LPHC diet did not affect the p70 ${ }^{\text {S6K }}$ content (Fig. 6B). No difference was observed in the GSK-3 and p-GSK-3/GSK-3 ratio in the EDL muscles between the LPHC and $\mathrm{C}$ rats (Fig. 6C).

We investigated the AMPK and p-AMPK contents because this kinase has an important role in the inhibition of protein synthesis by suppression of the function of multiple translation regulatory factors. Neither the AMPK protein content nor the p-AMPK/AMPK ratio was altered by treatment with the LPHC diet for 15 days (Fig. 6D).

The cAMP-response-element binding protein CREB is a wellknown transcription factor target of the cAMP-dependent protein kinase PKA and is considered the major effector of CAMP in skeletal muscles. The CREB levels were similar in the EDL muscle of the two groups. However, the LPHC diet reduced the levels of phosphorylated CREB by $48 \%$ (Fig. 6 E).

\subsection{Basal and phosphorylated content of Foxo1 (regulation of proteolysis)}

The Foxo1 factor is implicated in the reduction of muscle protein breakdown by reduction of atrogene expression via Akt. The Foxo1 content was not altered by the diet, but the Foxo1 phosphorylation was $85 \%$ higher in the EDL muscles of the LPHC rats than in the $C$ rats (Fig. 7).
Table 2

The total food and protein intake, initial and final body weights, mass and protein content of the EDL muscle of low-protein, high-carbohydrate (LPHC) rats and those of control rats after 15 days of treatment

\begin{tabular}{lcc}
\hline Parameter & Control & LPHC \\
\hline Initial body weight $(\mathrm{g})$ & $93.57 \pm 1.14$ & $93.08 \pm 1.41$ \\
Final body weight $(\mathrm{g})$ & $191.52 \pm 2.95$ & $148.05 \pm 6.88^{*}$ \\
Total food intake $(\mathrm{g})$ & $216.69 \pm 6.32$ & $244.96 \pm 9.57^{*}$ \\
Total protein intake $(\mathrm{g})$ & $36.83 \pm 1.02$ & $14.70 \pm 0.61^{*}$ \\
EDL mass $(\mathrm{g})$ & $0.176 \pm 0.012$ & $0.113 \pm 0.005^{* *}$ \\
Muscle protein content $(\mathrm{mg} / \mathrm{g}$ muscle) & $213.50 \pm 8.24$ & $140.98 \pm 8.98^{* *}$ \\
\hline
\end{tabular}

The data are the mean \pm SEM of rats ( $n=8-10$ rats).

* $P<.05$ vs. control rats:

** $P<.01$ vs. control rats (Student's $t$ test).

\section{Discussion}

In vivo and in vitro experiments were performed in the present study with the objective of obtaining insight into the protein metabolism in EDL muscles of growing rats adapted to the LPHC diet. Our investigation showed a reduction in the mass and protein content of the EDL muscle of LPHC rats compared with $\mathrm{C}$ rats. Thus, initially, we evaluated the in vitro basal protein synthesis and proteolysis in EDL muscles from LPHC and C rats using specific media for each evaluations. We observed that the EDL muscle from the LPHC rats showed less incorporation of ${ }^{14} \mathrm{C}$-tyrosine and also less tyrosine release in the medium, suggesting lower protein synthesis and proteolysis, respectively. However, the reduction in the ${ }^{14} \mathrm{C}-$ tyrosine incorporation by the muscle was higher than the reduction in the tyrosine release by the incubated muscle. These results can explain the reduction in the EDL muscle mass. Batistela et al. [14] performed the same analyses in the same conditions in the soleus muscle of LPHC rats. Comparing our EDL data with the data obtained from the soleus muscle [14], we observed that the reduction in the protein synthesis was lower in the soleus $(\sim 19 \%)$ than in the EDL $(\sim 34 \%)$, whereas the inhibition of the protein breakdown was more pronounced in the soleus muscles $(\sim 36 \%)$ than in the EDL $(\sim 22 \%)$. These results are consistent with the higher mass loss of EDL compared with the soleus muscle in LPHC rats: $37 \%$ and $27 \%$, respectively. The fact that the changes in the activity of these two processes define the mass of the muscle is also valid for other muscles and in other situations. Millward et al. [12] observed that, in the gastrocnemius and quadriceps skeletal muscles of rats fed a diet composed of $6.8 \%$ protein, the reduced mass observed in those muscles resulted from the reduction in the rates of both protein synthesis and breakdown.

Interestingly, EDL muscles of the LPHC rats showed higher insulin sensitivity, as evidenced by higher levels of insulin-stimulated Akt phosphorylation. After binding to its receptor in the plasma membrane of cells, insulin causes receptor autophosphorylation and activation of the signaling cascade, thus activating mTOR via Akt. mTOR plays a critical role in the regulation of protein synthesis and in the hypertrophy of skeletal muscles [18] because it promotes enhanced translation through its downstream targets, the $70-\mathrm{kDa}$ ribosomal protein $\mathrm{S} 6$ kinase $\left(\mathrm{p} 70^{\mathrm{S} 6 \mathrm{~K}}\right.$ ) and the eukaryotic initiation factor $4 \mathrm{E}$-binding protein (4E-BP1), which has a main role in the activation of the initiation stage of the translation process in eukaryotic cells. However, our results showed that the levels of phosphorylated $\mathrm{p} 70^{\mathrm{S} 6 \mathrm{~K}}$ and phosphorylated $4 \mathrm{E}-\mathrm{BP} 1$ in the EDL muscles of LPHC rats were both reduced although the insulin signaling is increased, which explains the lower rate of protein synthesis despite the increase in Akt phosphorylation. Thus, it is clear that, in addition to insulin, other factors can affect or stimulate protein synthesis. In our experimental animal, the amino acid availability seems to be a limiting factor. Nave et al. [36] showed in mammal cells that both the mTOR phosphorylation and the protein synthesis that occurred in response 
A

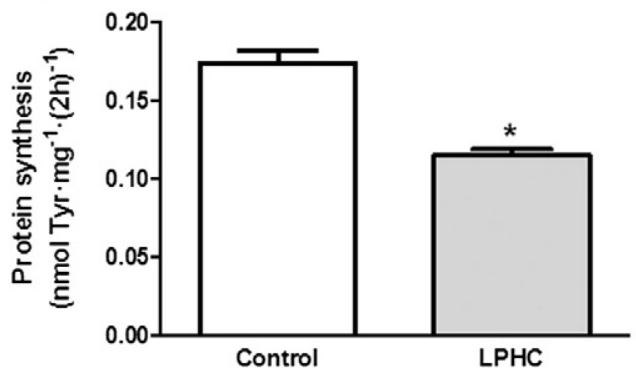

B

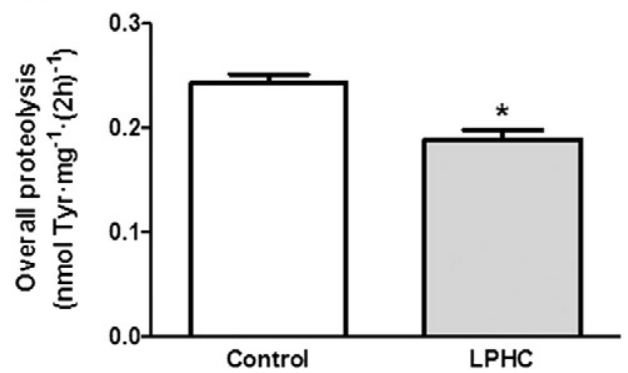

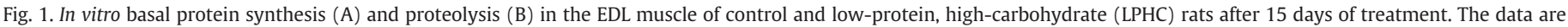
presented as the mean \pm SE ( $n=6-8$ rats per group). ${ }^{*} P<.05$ versus control diet (Student's $t$ test).

to insulin were blocked by amino acid deprivation, showing that mTOR represents a potential integration point of signals from insulin and amino acids. The administration of essential amino acids, mainly leucine, also results in an increase in the protein synthesis in skeletal muscle through activation of the mTOR pathway $[37,38]$. Moreover, in situations when the protein synthesis in rat skeletal muscle is lower due to a low level of protein in the diet, it is possible to reverse the reduction in the protein synthesis by supplementation with leucine [39] or lysine [40]. Previously, we demonstrated that, in the postfeeding period of LPHC rats, the plasma levels of lysine were unaffected, but the leucine levels were reduced by $30 \%$ compared with the value in control rats [14] (data are shown in
Table S3 of the supplementary material). Taken together, these data suggest that the reduced levels of leucine may represent an important factor in the reduction of the protein synthesis in the EDL muscles of LPHC rats. Additional experiments are necessary to prove this possibility.

For proteolytic pathways, our data showed that the contents of autophagy-related genes (LC3 and GABARAP) and cathepsin L, as well as the cathepsin B activity, remained unchanged in LPHC rats compared with $\mathrm{C}$ rats. These data suggest that the lysosomal proteolytic system is not involved in the reduction of the EDL skeletal muscle of LPHC rats. However, the inhibition of both the caspase-3 activity and ubiquitin-proteasome system in the EDL muscle of LPHC
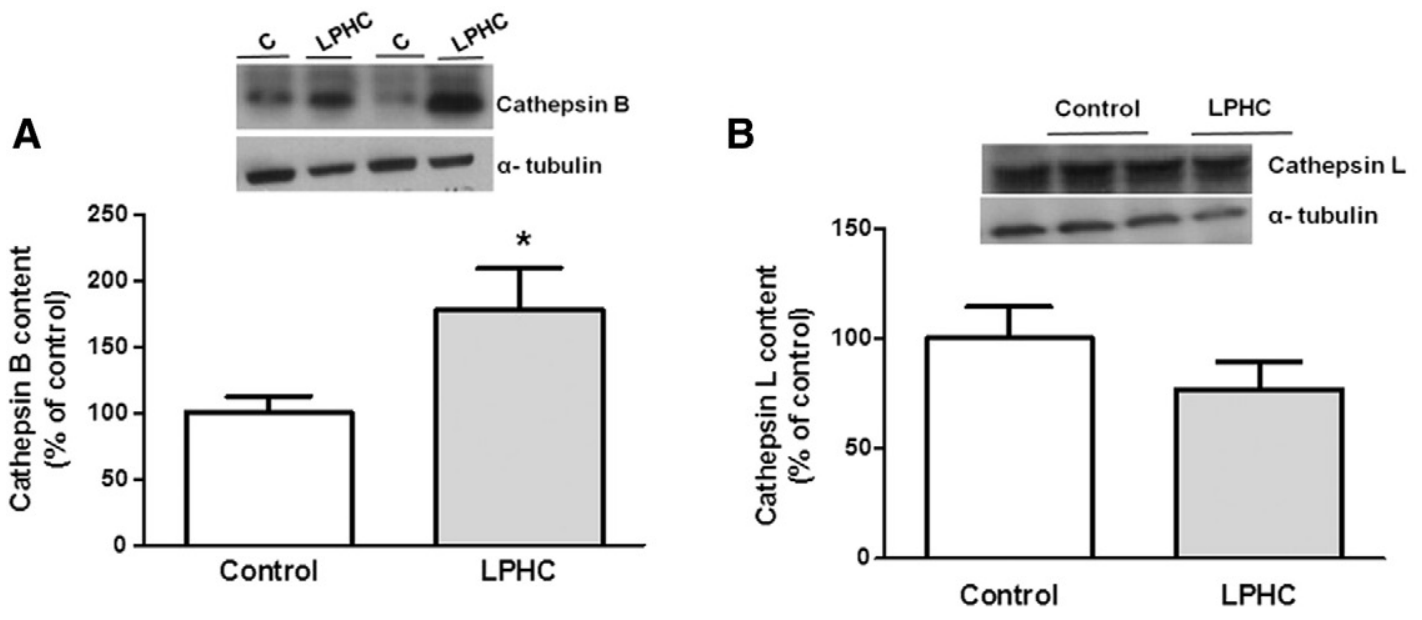

C

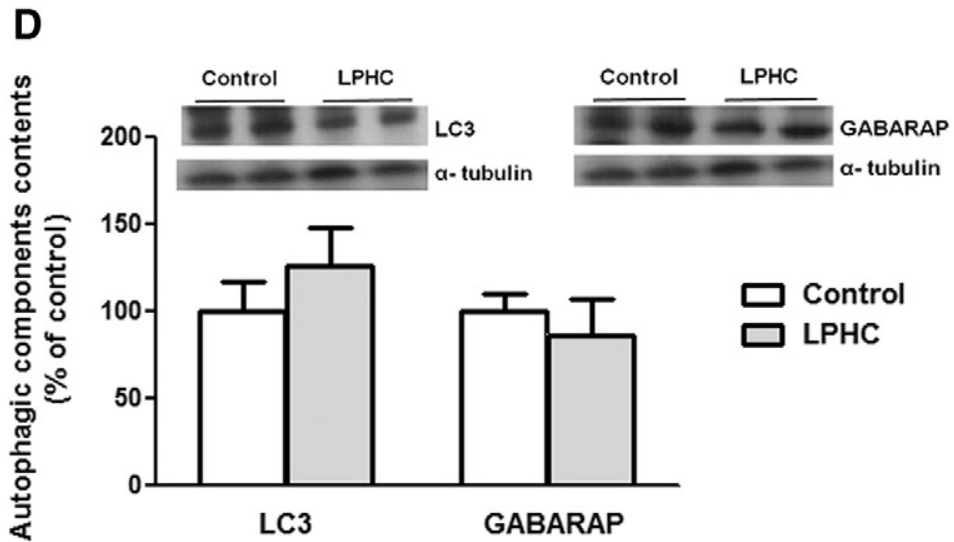

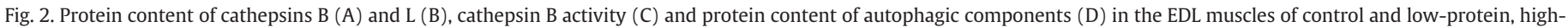
carbohydrate (LPHC) rats after 15 days of treatment. The data are presented as the mean \pm SE ( $n=6-8$ rats per group). ${ }^{*} P<.05$ versus control diet (Student's $t$ test). 
A

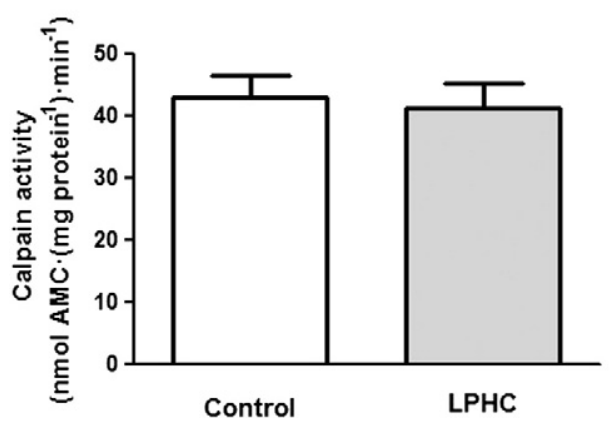

B

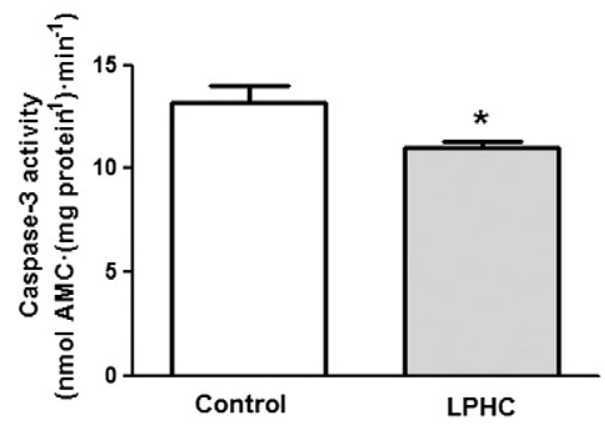

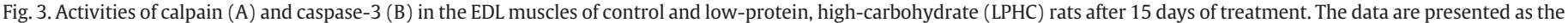
mean \pm SE ( $n=8-10$ rats per group). ${ }^{*} P<.05$ versus control diet (Student's $t$ test).

rats can reinforce the reduced proteolysis observed in the EDL muscle in vitro. The inhibition of the ubiquitin-proteasome system was evidenced by the decreases in both the atrogin- 1 content and the chymotrypsin-like proteasome activity. The expression of atrogenes, including atrogin-1, is inhibited by the PI3K/Akt insulin signaling, which is responsible for the phosphorylation of the nuclear Foxo transcription factor, which is excluded from the nucleus when phosphorylated [41]. Our data showed that the EDL muscles from LPHC rats had an increase in the phosphorylation of Foxo1 accompa- nied by a reduction in the atrogin- 1 content, representing a minor decrease in the amount of substrates that are offered to the proteasome. These novel results reinforce the data obtained from the in vitro evaluation of proteolysis, when we observed lower tyrosine release in the medium, and this finding is consistent with the higher insulin-stimulated Akt phosphorylation in the EDL muscle of LPHC rats.

The proteasome is unable to degrade intact myofibrils [42], so upstream proteases are responsible for the release of myofibrillar
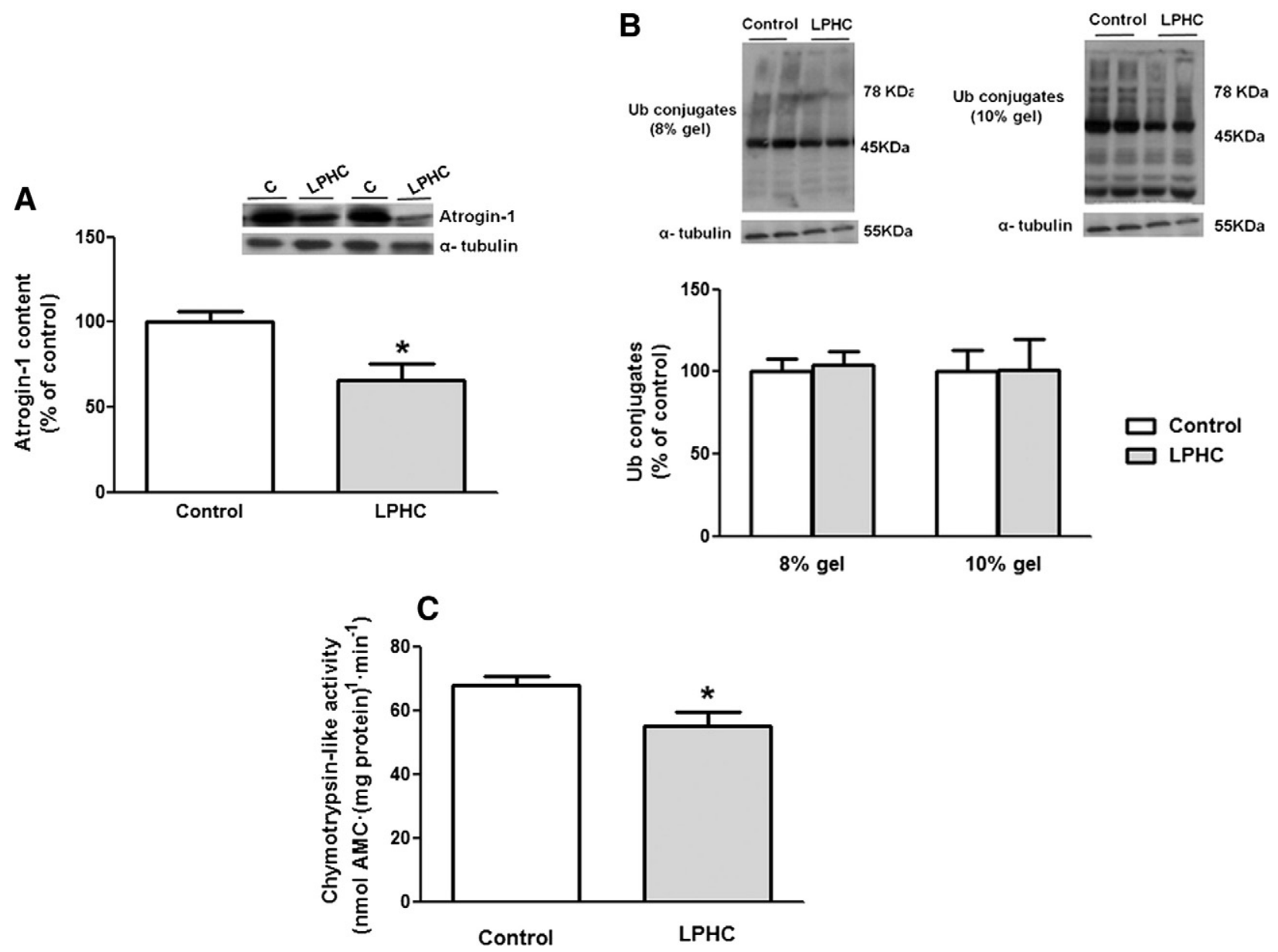

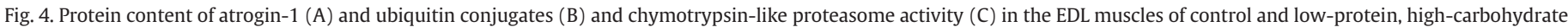
(LPHC) rats after 15 days of treatment. The data are presented as the mean \pm SE $(n=8-10$ rats per group). * P<.05 versus control diet (Student's $t$ test). 

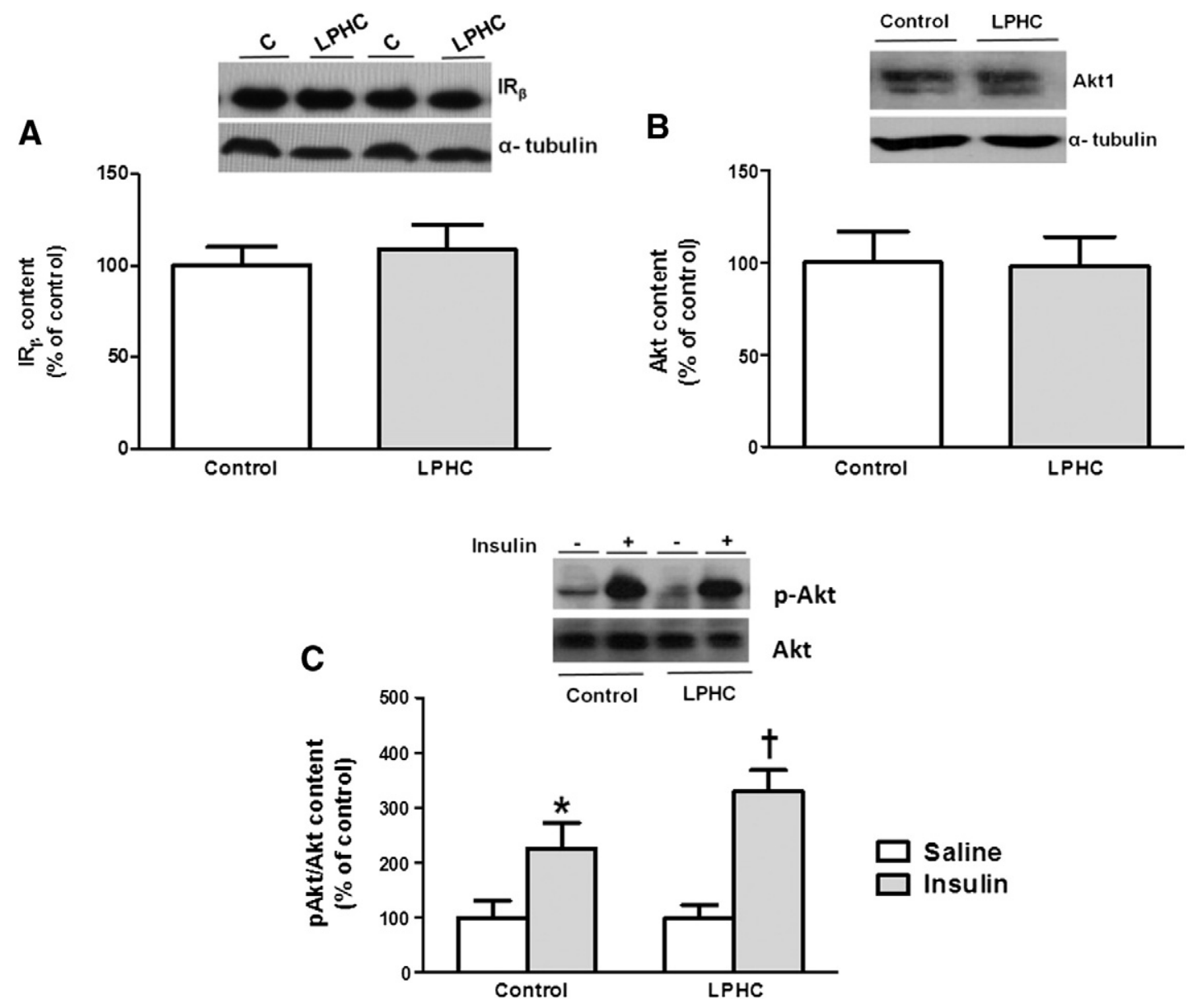

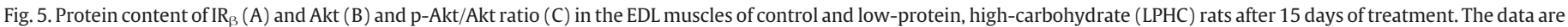
presented as the mean $\pm \mathrm{SE}\left(\mathrm{n}=5-7\right.$ rats per group). ${ }^{*} \mathrm{P}<.05$ versus control saline (Student's $\mathrm{t}$ test). ${ }^{\dagger} \mathrm{P}<.05$ versus LPHC saline (Student's $\mathrm{t}$ test).

proteins from the sarcomere for the subsequent ubiquitination and proteasomal degradation. Calpains [43] and caspase-3 [22,44] are involved in the dissociation of myofibrils. According to our data, the activity of calpains was unchanged in the EDL muscles of LPHC rats, but a reduction in the caspase- 3 activity was observed. Insulin has been also reported as an inhibitor of caspase-3 in skeletal muscles. Under muscle atrophy conditions, such as diabetes or chronic uremia, the accumulation of a 14-kDa actin fragment generated by the cleavage of actomyosin and cleaved by caspase- 3 is observed [22]. When incubated in medium lacking metabolic substrates, L6 muscle cells showed an increase in actin cleavage; however, when insulin was added to the medium, the actin cleavage was blocked by a mechanism requiring PI3K [22]. Thus, it can be concluded that the decreased activity of caspase- 3 in association with the decreased expression of atrogin-1 may be related the decreased availability of substrates for the proteasome in the EDL of LPHC rats. In the soleus muscle of LPHC rats, Batistela et al. [14] also observed similar changes in the proteolytic pathways and higher insulin sensitivity, with an increase in the $\mathrm{IR}_{\beta}$ content and in the insulin-stimulated Akt phosphorylation. However, in contrast to the findings in EDL muscle, the AMPK and p-AMPK content in the soleus muscle increased. Studies have shown that AMPK enhances the insulin sensitivity of some skeletal muscles $[45,46]$, and this effect has an important role in the inactivation of proteolysis and other catabolic pathways.

As we previously noted, LPHC rats showed an increase in the circulating levels of corticosterone, TNF- $\alpha$ [16] and leptin [13] (Table S2; supplementary material), which have an inhibitory effect on protein synthesis. The results obtained in this present study suggested that these factors do not seem to have a significant effect on the reduced protein synthesis in the EDL muscle. The inhibitory action of TNF- $\alpha$ on protein synthesis occurs mainly via inhibition of the phosphorylation of IRS-1 at Ser307 [47], thus preventing the activation of other proteins downstream of insulin signaling, such as Akt. In this study, we did not find changes in the basal p-Akt content of the EDL muscles of LPHC rats, suggesting that, despite the increase in the serum TNF- $\alpha$ level in LPHC rats, this cytokine did not inhibit the insulin signaling in the tissue. The inhibitory effect of glucocorticoids

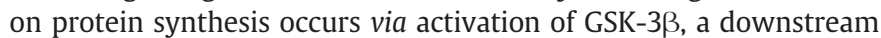
target of insulin/Akt signaling that suppresses protein synthesis by inhibiting the eukaryotic transcription factor 2B-dependent translation (eIF2B) [48]. In contrast, leptin decreases protein synthesis by impairing mTOR phosphorylation through activation of the AMPK pathway $[49,50]$. In the present study, we did not observe changes in the GSK-3 $\beta$ and AMPK contents or in the phosphorylation levels of these proteins in the EDL muscles of LPHC rats. This fact suggests that the high levels of corticosterone and leptin in LPHC rats are not a determining factor in the reduction of the protein synthesis in EDL muscle.

LPHC rats exhibited higher epinephrine and norepinephrine levels (Table S2; supplementary material) [15]. Numerous studies have shown that the administration of $\beta_{2}$-agonists positively regulates skeletal muscle mass [41,51]. The $\beta_{2}$-adrenergic signaling pathway involves the activation of the $G \alpha_{s}$ protein, which in turn activates adenylate cyclase, resulting in increased cAMP production. Cyclic AMP-activated PKA initiates the transcription of many target 

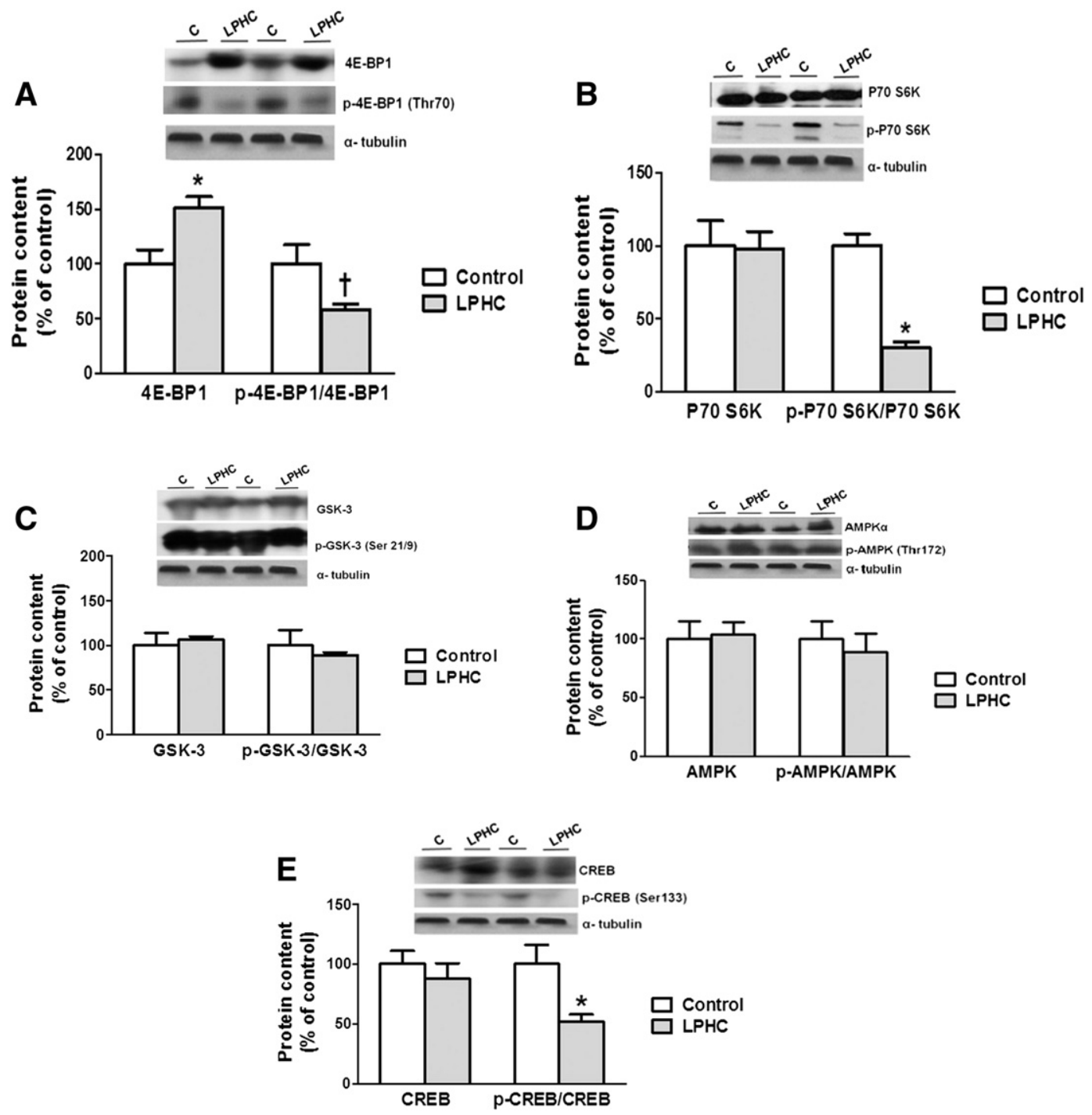

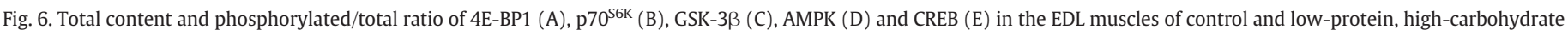

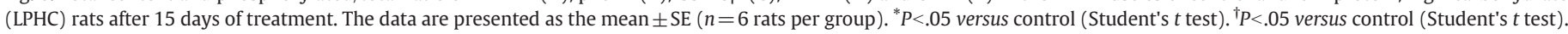

genes via the phosphorylation of CREB at Ser133. In fact, CREB phosphorylation occurs rapidly in skeletal muscles in response to $\beta_{2}$-adrenergic stimuli [51]. Furthermore, $\beta_{2}$-adrenergic stimulation in skeletal muscle leads to the release of the $\mathrm{G}_{\beta_{\gamma}}$ subunit, which in turn activates PI3K/Akt/mTOR signaling and thus induces protein synthesis [51]. In the present study, a $48 \%$ reduction in the phosphorylation of CREB in the EDL muscles of LPHC rats was observed. In addition, the unaltered basal p-Akt levels suggest that

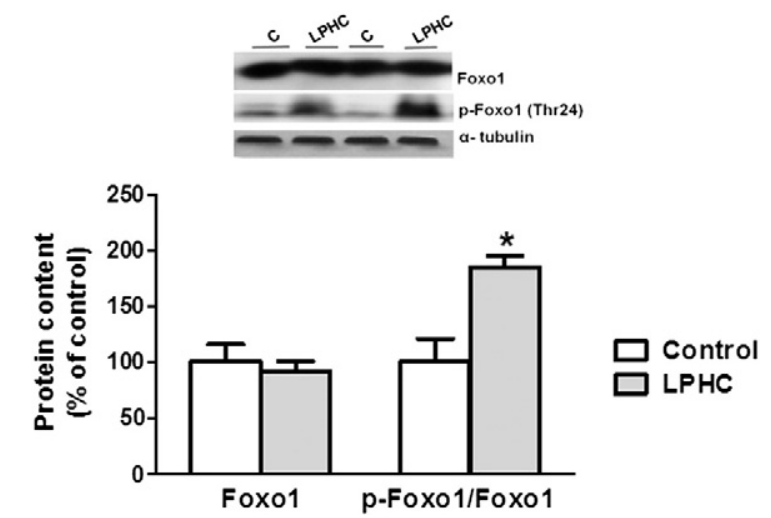

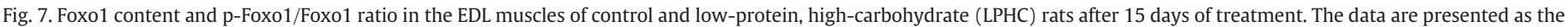
mean \pm SE ( $n=6$ rats per group). ${ }^{*} P<.05$ versus control diet (Student's $t$ test). 
$\beta_{2}$-adrenergic stimulation is not evoked in the EDL muscles of LPHC rats despite the increase in plasma catecholamine levels, suggesting that adrenergic signaling was not involved in the reduction of protein synthesis.

Thus, our results suggest that, despite the changes in the circulating levels of hormones and proinflammatory cytokines in LPHC rats, which strongly influenced the carbohydrate and lipid metabolism in the liver [52] and adipose tissues that were already reported in other studies $[15,16,53]$, these factors are not the main determinants of protein metabolism in the EDL muscle.

In summary, the following can be concluded:

(i) The increase in the insulin sensitivity of EDL muscles of the LPHC rats contributes to the reduced proteolysis through a reduction in the activity of caspase- 3 and the ubiquitinproteasome system.

(ii) The lower rate of protein synthesis in the EDL muscle of LPHC rats is probably linked to inhibition of the phosphorylation of mTOR as a consequence of the lower availability of specific amino acids, suggesting that the protein synthesis is directly affected by the quantity and quality of the amino acids from dietary protein.

\section{Acknowledgments}

The authors acknowledge Air Francisco Costa, Celso Roberto Afonso and Cristina Helena Alves for their technical assistance. This work was supported by grants from the Fundação de Amparo a Pesquisa do Estado de Mato Grosso (FAPEMAT 286326/2010 and FAPEMAT 222560/2015).

\section{Appendix A. Supplementary data}

Supplementary data to this article can be found online at http://dx. doi.org/10.1016/j.jnutbio.2016.04.008.

\section{References}

[1] Patel MS, Srinivasan M. Metabolic programming in the immediate postnatal life. Ann Nutr Metab 2011;58:18-28.

[2] Steyn NP, Mchiza Z, Hill J, Davids YD, Hinrichsen E, Opperman M, et al. Nutritional contribution of street foods to the diet of people in developing countries: a systematic review. Public Health Nutr 2013;17:1-12.

[3] Frontera WR, Ochala J. Skeletal muscle: a brief review of structure and function. Calcif Tissue Int 2015;96:183-95.

[4] Liu Z, Long W, Fryburg DA, Barrett EJ. The regulation of body and skeletal muscle protein metabolism by hormones and amino acids. J Nutr 2006;136: 212S-7S.

[5] Schiaffino S, Dyar KA, Ciciliot S, Blaauw B, Sandri M. Mechanisms regulating skeletal muscle growth and atrophy. FEBS J 2013;280:4294-314.

[6] Matsakas A, Patel K. Skeletal muscle fibre plasticity in response to selected environmental and physiological stimuli. Histol Histopathol 2009;24:611-29.

[7] Prescod AL, Halliday WC, Taylor CG. Protein deficiency, but not zinc deficiency, reduces recovery of type 1 and type 2 muscle fibre diameters in the gastrocnemius muscle of growing rats. Br J Nutr 2011;106:675-82.

[8] Alves AP, Dâmaso AR, Dal PV. The effects of prenatal and postnatal malnutrition on the morphology, differentiation, and metabolism of skeletal striated muscle tissue in rats. J Pediatr 2008;84:264-71.

[9] Kim JY. Hindlimb muscle atrophy occurs from short-term undernutrition in rats. Biol Res Nurs 2013;15:459-64.

[10] Tawa Jr NE, Goldberg AL. Suppression of muscle protein turnover and amino acid degradation by dietary protein deficiency. Am J Physiol 1992;263:E317-25.

[11] Da Silva AR, Guzmán-Quevedo O, Pérez-García G, Toscano AE, Gois Leandro C, Manhães-de-Castro R, et al. Differential developmental programming by early protein restriction of rat skeletal muscle according to its fibre-type composition. Acta Physiol 2014;210:70-83.

[12] Millward DJ, Garlick PJ, Stewart RJ, Nnanyelugo DO, Waterlow JC. Skeletal-muscle growth and protein turnover. Biochem J 1975;150:235-43.

[13] Aparecida de França S, Dos Santos MP, Garófalo MA, Navegantes LC, Kettelhut Ido $\mathrm{C}$, Lopes $\mathrm{CF}$, et al. Low protein diet changes the energetic balance and sympathetic activity in brown adipose tissue of growing rats. Nutrition 2009;25:1186-92.
[14] Batistela E, Pereira MP, Siqueira JT, Paula-Gomes S, Zanon NM, Oliveira EB, et al. Decreased rate of protein synthesis, caspase-3 activity, and ubiquitin-proteasome proteolysis in soleus muscles from growing rats fed a low-protein, highcarbohydrate diet. Can J Physiol Pharmacol 2014;92:445-54.

[15] Buzelle SL, Santos MP, Baviera AM, Lopes CF, Garófalo MA, Navegantes LC, et al. A low-protein, high-carbohydrate diet increases the adipose lipid content without increasing the glycerol-3-phosphate or fatty acid content in growing rats. Can J Physiol Pharmacol 2010;88:1157-65.

[16] Santos MP, França SA, Santos JT, Buzelle SL, Bertolini GL, Garófalo MA, et al. A lowprotein, high-carbohydrate diet increases fatty acid uptake and reduces norepinephrine-induced lipolysis in rat retroperitoneal white adipose tissue. Lipids 2012;47:279-89.

[17] Pasiakos SM, McClung JP. Supplemental dietary leucine and the skeletal muscle anabolic response to essential amino acids. Nutr Rev 2011;69:550-7.

[18] Yoshizawa F. Regulation of protein synthesis by branched-chain amino acids in vivo. Biochem Biophys Res Commun 2004;313:417-22.

[19] Dupont E, Cieniewski-Bernard C, Bastide B, Stevens L. Electrostimulation during hindlimb unloading modulates PI3K-AKT downstream targets without preventing soleus atrophy and restores slow phenotype through ERK. Am J Physiol Regul Integr Comp Physiol 2011;300:R408-17.

[20] Bodine SC, Baehr LM. Skeletal muscle atrophy and the E3 ubiquitin ligases MuRF1 and MAFbx/atrogin-1. Am J Physiol Endocrinol Metab 2014;307:E469-84.

[21] Bechet D, Tassa A, Taillandier D, Combaret L, Attaix D. Lysosomal proteolysis in skeletal muscle. Int J Biochem Cell Biol 2005;37:2098-114.

[22] Du J, Wang X, Miereles C, Bailey JL, Debigare R, Zheng B, et al. Activation of caspase- 3 is an initial step triggering accelerated muscle proteolysis in catabolic conditions. J Clin Invest 2004;113:115-23.

[23] Smith IJ, Dodd SL. Calpain activation causes a proteasome-dependent increase in protein degradation and inhibits the AKT signaling pathway in rat diaphragm muscle. Exp Physiol 2007:92:561-73.

[24] Mizushima N, Yamamoto A, Matsui M, Yoshimori T, Ohsumi Y. In vivo analysis of autophagy in response to nutrient starvation using transgenic mice expressing a fluorescent autophagosome marker. Mol Biol Cell 2004;15:1101-11.

[25] Llovera M, Garcia-Martinez C, Agell N, Lopez-Soriano FJ, Argiles JM. Muscle wasting associated with cancer cachexia is linked to an important activation of the ATPdependent ubiquitin-mediated proteolysis. Int J Cancer 1995;29(61):138-41.

[26] Graça FA, Gonçalves DA, Silveira WA, Lira EC, Chaves VE, Zanon NM, et al. Epinephrine depletion exacerbates the fasting-induced protein breakdown in fast-twitch skeletal muscles. Am J Physiol Endocrinol Metab 2013;305:E1483-94.

[27] Bradford MM. A rapid and sensitive method for the quantitation of microgram quantities of protein utilizing the principle of protein-dye binding. Anal Biochem 1976;72:248-54.

[28] Navegantes LC, Resano NM, Baviera AM, Migliorini RH, Kettelhut IC. Effect of sympathetic denervation on the rate of protein synthesis in rat skeletal muscle. Am J Physiol Endocrinol Metab 2004;286:E642-7.

[29] Scharff R, Wool IG. Effect of diabetes on the concentration aminoacids in plasma and heart muscle of rats. Biochem J 1966;99:173-8.

[30] Pepato MT, Migliorini RH, Goldberg AL, Kettelhut IC. Role of different proteolytic pathways in degradation of muscle protein from streptozotocin-diabetic rats. Am J Physiol 1996;271:E340-7.

[31] Waalkes TP, Udenfriend S. A fluorimetric method for the estimation of tyrosine in plasma and tissues. J Lab Clin Med 1957;50:733-6.

[32] Klaude M, Fredriksson K, Ader ITJ, Hammarqvist F, Ahlmans B, Rooyackers O, et al. Proteasome proteolytic activity in skeletal muscle is increased in patients with sepsis. Clin Sci 2007;112:499-506.

[33] Douillard A, Galbes O, Begue G, Rossano B, Levin J, Vernus B, et al. Clin Exp Pharmacol Physiol 2012;39:364-72.

[34] Barret AJ, Kirschke H. Cathepsin B, cathepsins H and cathepsins L. Methods Enzymol 1981;80:535-61.

[35] Scheibe PO. Number of samples - hypothesis testing. Nucl Med Biol 2008;35: 3-9.

[36] Nave BT, Ouwens DM, Withers DJ, Alessi DR, Shepherd PR. Mammalian target of rapamycin is a direct target for protein kinase $B$ : identification of a convergence point for opposing effects of insulin and amino acid deficiency on protein translation. Biochem J 1999;344:427-31.

[37] Crozier SJ, Kimball SR, Emmert SW, Anthony JC, Jefferson LS. Oral leucine administration stimulates protein synthesis in rat skeletal muscle. J Nutr 2005; 135:376-82.

[38] Donato Jr J, Pedrosa RG, Cruzat VF, Pires IS, Tirapegui J. Effects of leucine supplementation on the body composition and protein status of rats submitted to food restriction. Nutrition 2006;22:520-7.

[39] Gao X, Tian F, Wang X, Zhao J, Wan X, Zhang L, et al. Leucine supplementation improves acquired growth hormone resistance in rats with protein-energy malnutrition. PLoS One 2015;10:e0125023.

[40] Sato T, Ito Y, Takashi NT. Dietary l-lysine suppresses autophagic proteolysis and stimulates Akt/mTOR signaling in the skeletal muscle of rats fed a low-protein diet. J Agric Food Chem 2015;63:8192-8.

[41] Manfredi LH, Zanon NM, Garófalo MA, Navegantes LC, Kettelhut IC. Effect of shortterm cold exposure on skeletal muscle protein breakdown in rats. J Appl Physiol 2013;115:1496-505.

[42] Solomon V, Goldberg AL. Importance of the ATP-ubiquitin-proteasome pathway in the degradation of soluble and myofibrillar proteins in rabbit muscle extracts. J Biol Chem 1996;271:26690-7.

[43] Goll DE, Neti G, Mares SW, Thompson VF. Myofibrillar protein turnover: the proteasome and the calpains. J Anim Sci 2008;86:E19-35. 
[44] Lee SW, Dai G, Hu Z, Wang X, Du J, Mitch WE. Regulation of muscle protein degradation: coordinated control of apoptotic and ubiquitin-proteasome systems by phosphatidylinositol 3 kinase. J Am Soc Nephrol 2004;15: 1537-45.

[45] Towler MC, Hardie DG. AMP-activated protein kinse in metabolic control and insulin signaling. Circ Res 2007;100:328-41.

[46] Wang P, Zhang RY, Song J, Guan YF, Xu TY, Du H, et al. Loss of AMP-activated protein kinase impairs the insulin-sensitizing effect of calorie restriction in skeletal muscle. Diabetes 2012;61:1051-61.

[47] Hotamisligil GS, Peraldi P, Budavari A, Ellis R, White MF, Spiegelman BM. IRS-1-mediated inhibition of insulin receptor tyrosine kinase activity in TNF-alpha- and obesity-induced insulin resistance. Science 1996;271: 665-8.

[48] Jefferson LS, Fabian JR, Kimball SR. Glycogen synthase kinase-3 is the predominant insulin-regulated eukaryotic initiation factor 2B kinase in skeletal muscle. Int J Biochem Cell Biol 1999;31:191-200.
[49] Miyazaki M, Esser KA. Cellular mechanisms regulating protein synthesis and skeletal muscle hypertrophy in animals. J Appl Physiol 2009;106:1367-73.

[50] Berdeaux R, Stewart R. Intracellular signal for skeletal muscle adaptation cAMP signaling in skeletal muscle adaptation: hypertrophy, metabolism, and regeneration. Am J Physiol Endocrinol Metab 2012;303:E1-17.

[51] Sato S, Shirato K, Tachiyashiki K, Imaizumi K. Muscle plasticity and - $\beta 2$ adrenergic receptors: adaptive responses of $\beta 2$-adrenergic receptor expression to muscle hypertrophy and atrophy. J Biomed Biotechnol 2011;2011:729598.

[52] Menezes AL, Pereira MP, Buzelle SL, Dos Santos MP, de França SA, Baviera AM et al. A low-protein, high-carbohydrate diet increases de novo fatty acid synthesis from glycerol and glycerokinase content in the liver of growing rats. Nutr Res 2013;33:494-502.

[53] Aparecida de França S, Pavani Dos Santos M, Nunes Queiroz da Costa RV, Froelich M, Buzelle SL, Chaves VE, et al. Low-protein, high-carbohydrate diet increases glucose uptake and fatty acid synthesis in brown adipose tissue of rats. Nutrition 2014;30:473-80. 